\title{
A comparative study of patient characteristics, opinions, and outcomes, for patients who leave the emergency department before medical assessment
}

\author{
Jacqueline Fraser, $\mathrm{BN}^{* \dagger}$; Paul Atkinson, MB, BCh, BAO, MA ${ }^{\dagger \ddagger \S}$; Audra Gedmintas, MBBS**; Michael \\ Howlett, BSc, BM* ${ }^{* \S}$; Rose McCloskey, $\mathrm{PhD}^{*{ }^{\dagger \ddagger}}$; James French, $\mathrm{MD}^{* \dagger \S}$
}

\section{ABSTRACT}

Objective: The emergency department (ED) left-withoutbeing-seen (LWBS) rate is a performance indicator, although there is limited knowledge about why people leave, or whether they seek alternate care. We studied characteristics of ED LWBS patients to determine factors associated with LWBS.

Methods: We collected demographic data on LWBS patients at two urban hospitals. Sequential LWBS patients were contacted and surveyed using a standardized telephone survey. A matched group of patients who did not leave were also surveyed. Data were analysed using the Fisher exact test, chi-square test, and student t-test.

Results: The LWBS group $(n=1508)$ and control group ( $n=1504$ ) were matched for sex, triage category, recorded wait times, employment and education, and having a family physician. LWBS patients were younger, more likely to present in the evening or at night, and lived closer to the hospital. A long wait time was the most cited reason for leaving (79\%); concern about medical condition was the most common reason for staying (96\%). Top responses for improved likelihood of waiting were shorter wait times (LWBS, 66\%; control, 31\%) and more information on wait times $(41 \% ; 23 \%)$. A majority in both groups felt that their condition was a true emergency (63\%; 72\%). LWBS patients were more likely to seek further health care $(63 \%$ v. $28 \%$; $p<0.001$ ) and sooner (median time 1 day v. 2-4 days; $p=0.002$ ). Among patients who felt that their condition was not a true emergency, the top reason for ED attendance was the inability to see their family doctor (62\% in both groups). Conclusion: LWBS patients had similar opinions, experiences, and expectations as control patients. The main reason for LWBS was waiting longer than expected. LWBS patients were more likely to seek further health care, and did so sooner. Patients wait because of concern about their health problem. Shorter wait times and improved communication may reduce the LWBS rate.

\section{RÉSUMÉ}

Contexte: Le taux de départ sans examen médical (DSEM) au service des urgences (SU) est un indicateur de performance, mais on en connaît bien peu sur les raisons qui poussent les patients à partir ou sur la recherche ou non de formules de rechange. L'étude visait donc à caractériser les malades qui partent sans avoir été examinés afin de déterminer les facteurs associés au phénomène.

Méthode: II y a eu collecte de données démographiques sur les malades qui sont partis sans avoir été examinés dans deux hôpitaux urbains. On a communiqué avec ceux-ci en ordre séquentiel et l'on a procédé à une enquête téléphonique à l'aide d'un questionnaire uniforme. Par ailleurs, un groupe apparié de patients qui sont restés au SU ont également été soumis à l'enquête. Les données recueillies ont été analysées à l'aide de la méthode exacte de Fisher, du test du chi carré et du test de Student.

Résultats: Le groupe de DSEM ( $n=1508$ ) et le groupe témoin $(n=1504)$ ont été appariés en fonction du sexe, de la catégorie de triage, du temps d'attente enregistré, de l'emploi, du degré d'instruction et de la possibilité ou non de consulter un médecin de famille. Les patients du groupe de DSEM étaient plus jeunes que ceux de l'autre groupe et plus susceptibles de consulter le soir ou la nuit et de demeurer près de l'hôpital. Le motif de départ invoqué le plus souvent était un délai d'attente trop long (79\%); le motif d'attente invoqué le plus souvent était l'inquiétude causée par la gravité de l'affection (96\%). Les réponses mentionnées le plus souvent pour améliorer les probabilités d'attente au SU étaient une réduction des délais d'attente (DSEM : $66 \%$; témoin : $31 \%$ ) et plus de renseignements sur les délais d'attente (41\%; $23 \%)$. Dans les deux groupes, la majorité des participants estimaient qu'il s'agissait d'une véritable urgence (63\%; $72 \%$ ). Les patients du groupe de DSEM avaient tendance à rechercher une formule de rechange (63\% contre [c.] $28 \% ; p<0,001)$, et ce, plus rapidement que ceux de l'autre groupe (temps médian : 1 jour c. $2-4 ; p=0,002$ ). Parmi les

From the *Department of Emergency Medicine, Dalhousie University, Saint John, NB; †Horizon Health Network, Saint John Regional Hospital, Saint John, NB; ‡Department of Nursing and Health Sciences, University of New Brunswick, Saint John, NB; and §Discipline of Emergency Medicine, Memorial University, St. John's, NL.

Correspondence to: Paul Atkinson, Department of Emergency Medicine, Dalhousie University, Horizon Health Network, Saint John Regional Hospital, 400 University Avenue, Saint John, NB E2L 4L2; Email: Paul.atkinson@dal.ca 
patients qui estimaient que leurs ennuis de santé n'étaient pas une véritable urgence, la principale raison invoquée pour consulter au SU était I'impossibilité de voir un médecin de famille (62\% dans les deux groupes).

Conclusions: Les patients du groupe de DSEM avaient en commun les mêmes opinions, les mêmes expériences et les mêmes attentes que les témoins. Le principal motif invoqué par les patients du groupe de DSEM était un délai d'attente plus long que prévu. Par ailleurs, ces mêmes personnes étaient plus susceptibles de rechercher une formule de rechange de soins, et ce, plus rapidement que les témoins. Quant aux patients de l'autre groupe, ils attendaient en raison de l'inquiétude causée par leur affection. Des délais d'attente plus courts et de meilleures communications pourraient permettre une diminution du taux de DSEM.

Keywords: left without being seen (LWBS), triage, wait times

\section{INTRODUCTION}

Patients who present to an emergency department (ED) are assessed and treated according to a triage system that determines priority. ${ }^{1}$ This model often results in long waiting times, overcrowding, patient dissatisfaction, high walk-out or left-without-being-seen (LWBS) rates for those categorized as lower priority. ${ }^{1}$ Although LWBS rates are routinely tracked, monitored, and used as an indicator of ED performance, there is limited knowledge about why people leave or whether they seek alternate care.

The literature indicates that LWBS patients have conditions of lower urgency and lower acuity, are more likely to be male and younger, and are likely to identify prolonged waiting times as a central concern. ${ }^{2,3}$ Although there are reports of low rates of adverse health effects in the LWBS population, including lowreturn ED visits and hospitalizations, ${ }^{4,5}$ others report that LWBS patients often seek alternative medical attention and exhibit higher rates of ongoing symptoms at follow-up compared to those who wait. 6,7

In 2009-2010, the ED of our tertiary referral centre averaged LWBS rates of $9 \%-10 \%$; this number was more than three times the national average of $3 \%{ }^{8}$ In this study, we wished to determine factors contributing to the local LWBS rate. We also wished to compare LWBS patients to a similar group of triaged patients who did not leave to determine whether factors associated with leaving were intrinsic or extrinsic to patient characteristics. Finally, we were interested in determining the proportion of LWBS patients who sought further medical attention.

\section{METHODS}

We performed a cross-sectional survey and follow-up telephone survey of ED patients using a matched casecontrol design to compare characteristics, factors associated with LWBS and subsequent events for ED LWBS patients, with a demographically matched control group of patients who waited to be seen.

We collected demographic data over a 6-month period on 1508 LWBS patients in two urban hospitals located in one city; one hospital was a tertiary referral centre, and the other was an urgent care centre. Both hospitals use a standard process of tracking all LWBS patients, which includes monitoring all patients who leave the ED without being assessed by a physician, regardless of their triage level or reason for ED visit.

A total of 467 sequential LWBS patients were contacted and surveyed by nursing staff using a standardized telephone survey (Table 1). Nursing staff were not blinded to LWBS and control groups. Two attempts were made to contact each patient. Data on a matched control group of 1504 patients who did not leave the ED were collected, and 437 control patients were also surveyed. Matching was attempted for the triage category, employment and education, distance from hospital to home, and having a family physician. Re-attendance and readmissions were screened at both centres. Categorical data were analysed using chi-square and Fisher exact tests. Participation was voluntary and confidential. The study was approved by the Horizon Health Network Research Ethics Board. Because of the nature of the study and in compliance with national research guidelines, a request to waiver written consent was obtained by the institutional research ethics board.

\section{RESULTS}

Data from the cross-sectional survey confirmed that the LWBS group $(\mathrm{n}=1508)$ and the control group $(n=1504)$ were adequately matched for sex, triage category, and recorded wait times. Patients in the LWBS group were younger (32.6 v. 36.0 years; $p<0.0001)$ and 


\begin{tabular}{|c|c|}
\hline Control group (stayed) & Left-without-being-seen group (LWBS) \\
\hline 1. How long did you wait before being seen? & 1. How long was it before you left from the time you arrived at the ED? \\
\hline 2. What made you stay to see a doctor, despite the wait? & 2. What made you leave before a doctor saw you? \\
\hline 3. What could we have done to make your wait easier and more & 3. Did you tell any of the staff you were leaving? \\
\hline pleasant? & 4. What could we have done to make you wait longer to see \\
\hline 4. What was the outcome of your emergency department visit? & a doctor? \\
\hline $\begin{array}{l}\text { 5. Did you seek the advice of another health care professional? } \\
\text { If yes, what type of health care provider? }\end{array}$ & $\begin{array}{l}\text { 5. After you left, did you seek the advice of another health care } \\
\text { professional? }\end{array}$ \\
\hline Within what time frame? & If yes, what type of health care provider? \\
\hline 6. Did you see a health care provider or call telecare prior to coming & Within what time frame? \\
\hline to the emergency department? & What was the outcome of this visit? \\
\hline If yes, what type of care provider? & 6. Did you see a health care provider or call telecare prior to coming to \\
\hline $\begin{array}{l}\text { 7. Do you feel that your medical condition improved as a result of } \\
\text { being seen on that visit to the ED? }\end{array}$ & $\begin{array}{l}\text { the emergency department? } \\
\text { If yes, what type of care provider? }\end{array}$ \\
\hline $\begin{array}{l}\text { 8. What is the length of time you feel you should have waited with } \\
\text { your condition? }\end{array}$ & $\begin{array}{l}\text { 7. Do you feel that your medical condition worsened as a result of not } \\
\text { being seen on that visit to the ED? }\end{array}$ \\
\hline $\begin{array}{l}\text { 9. Do you feel your visit to the emergency department was a true } \\
\text { emergency? }\end{array}$ & $\begin{array}{l}\text { 8. What is the length of time you feel you should have waited with } \\
\text { your condition? }\end{array}$ \\
\hline $\begin{array}{l}\text { 10. If not, why did you present to the emergency department rather } \\
\text { than elsewhere? }\end{array}$ & $\begin{array}{l}\text { 9. Do you feel your visit to the emergency department was a true } \\
\text { emergency? }\end{array}$ \\
\hline 11. Which of the following statements do you think is most true? & $\begin{array}{l}\text { 10. If not, why did you present to the emergency department rather } \\
\text { than elsewhere? }\end{array}$ \\
\hline $\begin{array}{l}\text { b. Each condition should be seen within a certain time frame. } \\
\text { c. The sickest patients should be seen first, regardless of wait } \\
\text { times. }\end{array}$ & $\begin{array}{l}\text { 11. Which of the following statements do you think is most true? } \\
\text { a. Each patient should be seen in the order that they arrive. } \\
\text { b. Each condition should be seen within a certain time frame. }\end{array}$ \\
\hline 12. What is your employment status? & c. The sickest patients should be seen first, regardless of wait \\
\hline 13. What is the highest level of education you completed? & times. \\
\hline 14. How far is the hospital from your house? & 12. What is your employment status? \\
\hline $\begin{array}{l}\text { 15. Do you have a family doctor or nurse practitioner you are } \\
\text { registered with? }\end{array}$ & $\begin{array}{l}\text { 13. What is the highest level of education you completed? } \\
\text { 14. How far is the hospital from your house? }\end{array}$ \\
\hline 16. If not, are you on a waiting list for one? & $\begin{array}{l}\text { 15. Do you have a family doctor or nurse practitioner you are registered } \\
\text { with? } \\
\text { 16. If not are you on a waiting list for one? }\end{array}$ \\
\hline
\end{tabular}

more likely to present in the evening or at night (compared to daytime) than control patients (evening: LWBS 47.8\% v. control $39.2 \%$; day: LWBS $40.6 \%$ v. control $52.1 \%$; night: LWBS $11.6 \%$ v. control $8.7 \%$; chi-square test $40.37, p<0.0001$; Table 2). There was no difference in the cumulative percentage (fractile) wait times between LWBS patients and patients from the control group for each hour time period beyond the first hour (Figure 1).

Out of 1508 LWBS patients, we attempted to contact 1424; contact information was not available for the remaining 84 people. Of the 1424 patients, we were unable to contact 890 due to incorrect contact info or because they did not answer the phone, leaving 534 patients; 67 patients refused to participate, which left a total of 467 respondents in the LWBS group. Out of 1504 control patients, we attempted to contact 1414 .
Of those 1414 patients, we were unable to contact 915 due to incorrect contact information or because they did not answer the phone, leaving 499 patients; 62 patients refused to participate, which left 437 respondents in the control group (Figure 2).

Results from the telephone survey confirmed that the LWBS and control groups were similar for selfreported employment and education status, and for having a family physician. Patients in the LWBS group were more likely to report living closer than $20 \mathrm{~km}$ from the hospital (Table 3: LWBS 65.2\% v. control $54.3 \%$; OR [odds ratio] 1.6; 1.2-2.1; $p=0.001$ ) and had a longer mode self-reported waiting time range of 2-3 hours, compared with 1-2 hours for control patients waiting to be seen, and were more likely to report having waited longer than 2 hours (LWBS 65.2\% v. 


\begin{tabular}{|c|c|c|c|}
\hline \multirow[b]{2}{*}{ Characteristic } & \multicolumn{2}{|c|}{ Patients presenting to UCC and ED } & \multirow[b]{2}{*}{$\mathrm{P}$ value } \\
\hline & LWBS (1508) & Stayed (control-1504) & \\
\hline Age mean $(95 \% \mathrm{Cl} ; \mathrm{n})$ & $32.6(31.6-33.7 ; n=1508)$ & $36.0(34.8-37.1 ; n=1504)$ & $p<0.0001$ \\
\hline Sex, proportion male $(n)$ & $0.47(n=707)$ & $0.47(n=704)$ & $p=0.9963$ \\
\hline Wait time $(95 \% \mathrm{Cl})$ & 210 (179 to 241$)$ & 244 (129 to 359) & $p=0.5737$ \\
\hline Triage, proportion (n) & & & $p=0.9507$ \\
\hline Level 1 & $0.005(2)$ & $0.001(2)$ & \\
\hline Level 2 & $0.001(23)$ & $0.015(23)$ & \\
\hline Level 3 & $0.45(679)$ & $0.45(679)$ & \\
\hline Level 4 & $0.484(730)$ & $0.485(730)$ & \\
\hline Level 5 & $0.043(65)$ & $0.043(65)$ & \\
\hline No triage & $0.005(9)$ & $0.003(5)$ & \\
\hline \multicolumn{4}{|c|}{ Time of presentation, proportion $(95 \% \mathrm{Cl} ; \mathrm{n})$} \\
\hline Day & $0.41(0.38$ to $0.43 ; n=612)$ & $0.52(0.50$ to $0.55 ; n=783)$ & $p<0.0001$ \\
\hline Evening & $0.48(0.45$ to $0.50 ; n=721)$ & $0.39(0.37$ to $0.42 ; n=590)$ & $p<0.0001$ \\
\hline Night & $0.12(0.10$ to $0.13 ; n=175)$ & $0.09(0.07$ to $0.10 ; n=131)$ & $p=0.01$ \\
\hline
\end{tabular}

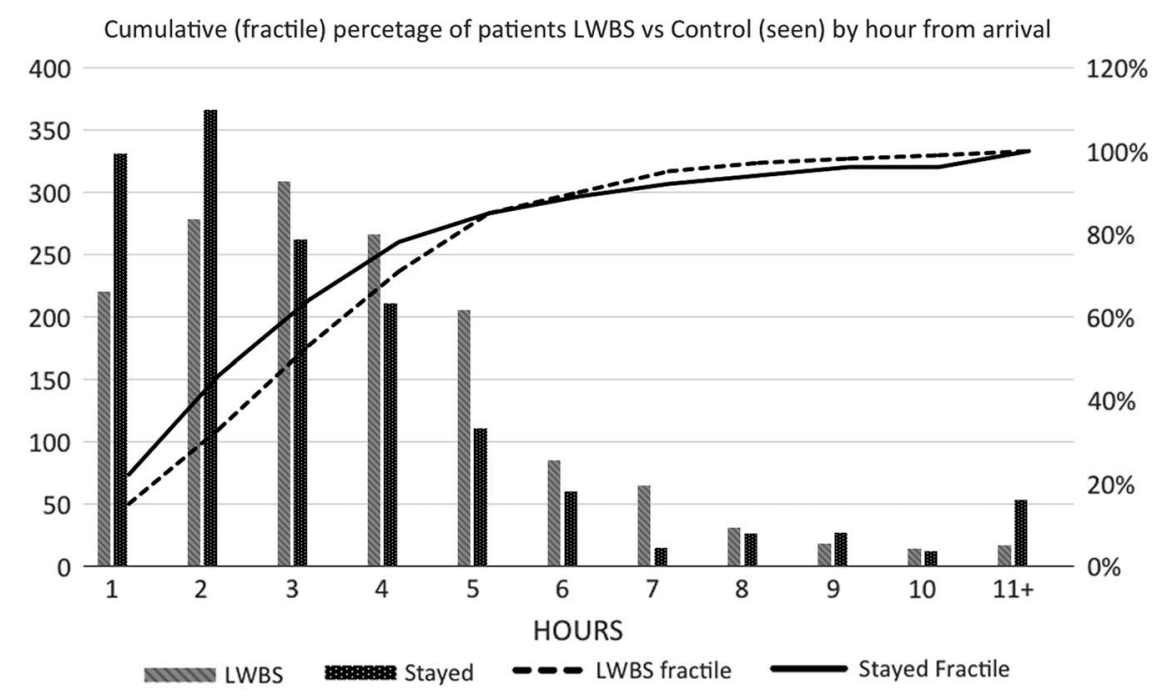

Figure 1. Cumulative (fractile) percentage of LWBS patients v. control patients (seen) by hour from arrival.

control 34.9\%; OR 3.5; 2.7-4.6; $p<0.0001$; see Table 3; Figure 3, A).

The most common reason reported (mode) for leaving was "long wait time" (79\%), and the reason for staying was "concern about medical condition" (96\%). The top response in both groups for how long patients considered to be an appropriate waiting time was "1-2 hours" (LWBS group 49\% v. control 35\%; see Table 3 and Figure 3, B), with no difference in the proportion of which patients felt that they should be seen in less than 2 hours (LWBS $83.4 \%$ v. control $87.5 \%$; OR $0.72 ; 0.48-1.1 ; p=0.12)$. The top responses given for what would have improved the likelihood of waiting, or what would have improved waiting conditions, were "shorter wait times" (LWBS 66\% v. control $31 \%$ ) and "more information on wait times" (LWBS $41 \%$ v. control 23\%; Figure 4).

The majority in both groups felt that their condition was a true emergency (LWBS 63\% v. control 72\%). LWBS patients were more likely to seek further health care (LWBS $63 \%$ v. control 28\%; $p<0.001$ ) and were more likely to do so sooner (Median time $1 \mathrm{v}$. 2-4 days; $p=0.002$ ). Of those who sought further health care, $44 \%$ followed up with a family doctor, $20 \%$ returned to the ED at a later time, $16 \%$ went to another ED, $16 \%$ went to an after-hours clinic, and the remaining $4 \%$ 


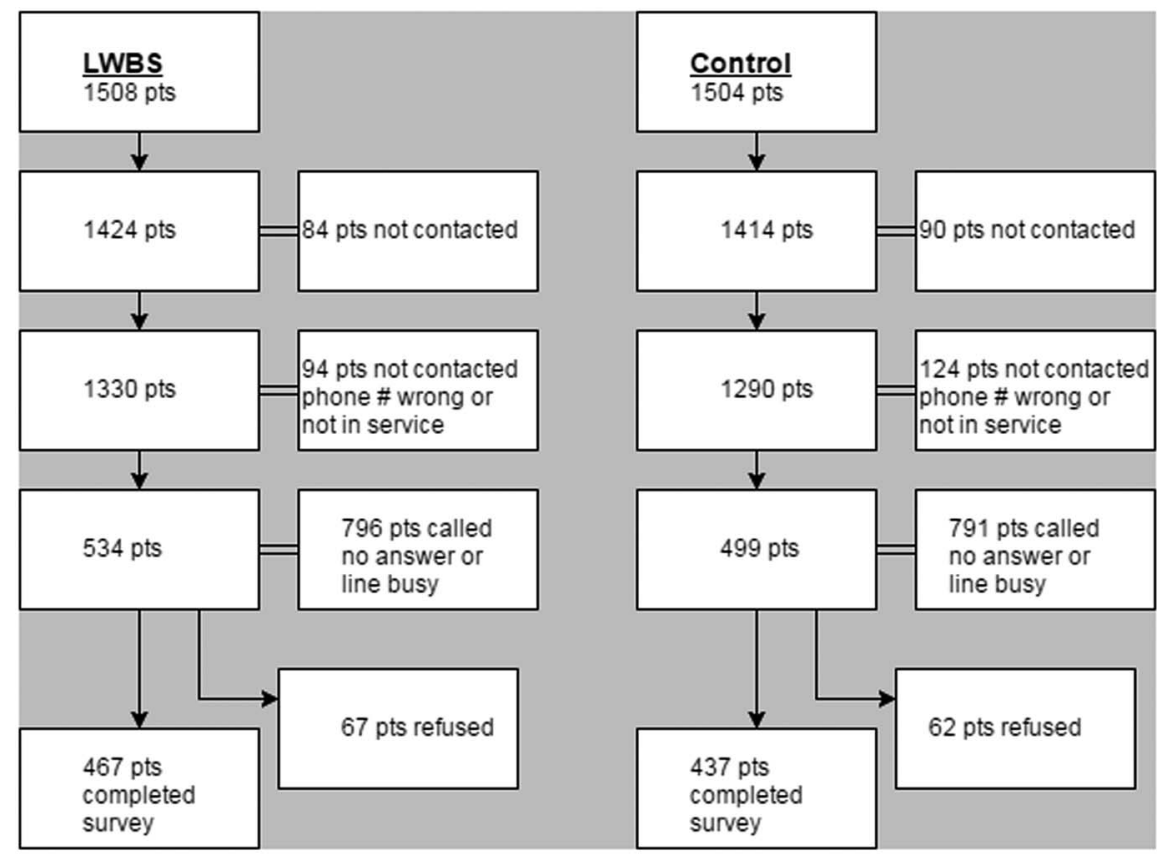

Figure 2. Study CONSORT diagram detailing the flow of left-without-being-seen (LWBS) patients and patients who stayed (control) through the study.

sought health care from "another allied health professional." The majority of these contacts were made the same day $(20 \%)$, the next day $(40 \%)$, or $2-4$ days after LWBS (27\%); the remaining patients (13\%) waited 4 days or more to contact a health care provider.

Of those patients who did not feel that their presentation was a true emergency (LWBS 37\%; control $28 \%$ ), the top reason given for ED attendance in both groups was the inability to see their family doctor (62\% and $62 \%$, respectively).

Fewer LWBS patients (7 [3\%]) later returned to the ED with the same problem and were admitted to the hospital compared to patients who stayed and were admitted during their initial ED visit (30 [7\%]; $p<0.0001$ ).

Only 4\% of patients believed patients should be seen in the order that they arrive, irrespective of their condition, whereas $82 \%$ believed that the sickest people should be seen first, regardless of wait times. Ten percent believed that each condition should be seen within a certain amount of time.

\section{DISCUSSION}

The objective fractile and median (control 244, minutes; LWBS, 210 minutes) wait time for LWBS and patients who were seen were similar, despite the difference in perceived wait time (median: control, 1-2 hours; LWBS, 2-3 hours). This is consistent with previous studies where objective and perceived wait times are not the same. The most commonly reported "reasonable" wait time for both groups was 1-2 hours, and the most common reason cited by patients as to the reason they left before assessment was a perceived long wait time. We demonstrated that LWBS patients leave when their perceived wait time exceeds their intrinsic wait time tolerance, because there was little difference in the extrinsic environment.

Although the most common change that patients stated that they would prefer was shorter waiting times, the next most popular suggested improvement was more information on waiting times. Published literature on consumer preferences indicates that improved communications and expectation setting are important for improved customer satisfaction., ${ }^{9,10}$ Providing accurate information on the estimated wait may be one way to alter patients' expectations of and tolerance for wait time, and thus change the rate of patients leaving.

The commonly cited reason of waiting too long to be seen is consistent with previously published reports on LWBS. ${ }^{11}$ Although the majority of our patients were triaged at a lower level, some were not, and 3\% ultimately required an inpatient hospital admission for the same issue. Particularly concerning is the large number 


\begin{tabular}{|c|c|c|c|}
\hline & \multicolumn{3}{|c|}{ Survey respondents presenting to UCC and ED } \\
\hline & LWBS (467) & Stayed (control 437) & $\mathrm{P}$ value \\
\hline Triage, proportion (n) & & & $p=0.718$ \\
\hline Level 1 & 0 & 0 & \\
\hline Level 2 & 1 & 5 & \\
\hline Level 3 & 244 & 227 & \\
\hline Level 4 & 207 & 187 & \\
\hline Level 5 & 10 & 12 & \\
\hline No triage & 5 & 6 & \\
\hline \multicolumn{4}{|l|}{ Distance of hospital from home } \\
\hline Less than $20 \mathrm{~km}$ & 302 & 234 & $p=0.001$ \\
\hline Greater than 20 km & 161 & 197 & \\
\hline \multicolumn{4}{|l|}{ Reported wait time } \\
\hline Under 2 hours & 155 & 274 & $p<0.0001$ \\
\hline Over 2 hours & 291 & 147 & \\
\hline \multicolumn{4}{|l|}{ Reported acceptable wait time } \\
\hline Under 2 hours & 317 & 328 & $p=0.115$ \\
\hline Over 2 hours & 63 & 47 & \\
\hline \multicolumn{4}{|l|}{ Registered with a primary care provider } \\
\hline Yes & 69 & 75 & $p=0.276$ \\
\hline No & 394 & 350 & \\
\hline \multicolumn{4}{|l|}{ Highest level of education completed } \\
\hline High school or less & 120 & 108 & $p=1.000$ \\
\hline Beyond high school & 150 & 133 & \\
\hline \multicolumn{4}{|l|}{ Employment status } \\
\hline Homemaker, retired, disability & 99 & 103 & $p=0.293$ \\
\hline Self-employed, student, works for company & 333 & 291 & \\
\hline (No reply) & 35 & 43 & \\
\hline
\end{tabular}

of our LWBS patients who could not be located. It cannot be assumed that these patients' conditions improved and/or that they did not experience a significant health event as a result of not being seen in the ED. This fact underscores the continued importance of LWBS, despite years of research in the issue ${ }^{7}$ and a need to address ED wait times.

Fewer LWBS patients were eventually admitted for their presenting problem compared to controls $(3 \% \mathrm{v}$. $7 \%$, respectively), suggesting that some patients may be able to self-triage. Our rate of ED return and subsequent hospital admission among LWBS patients is considerably lower than the $11 \%$ previously reported. ${ }^{6}$ It is possible that our ED is able to appropriately discern those who require immediate ED care from those who can wait.

A high percentage of all patients attended the ED because they were unable to see their primary care provider. Although limited access to primary care may be an important determinant of ED utilization, the fact that almost three-quarters of our LWBS patients perceived their condition as being a true emergency is particularly concerning. This finding suggests that LWBS is a high-risk group that deserves further attention. More important, it highlights that access to health care services in general can be problematic for many. LWBS is a complex issue that transcends multiple levels of the health care system and demands a multilevel response.

\section{LIMITATIONS}

Investigators conducting the telephone surveys were not blinded to a study group; however, because the structured survey tool was designed in advance, the major limitation is the reliability of the tool. The telephone surveys were completed with only one-third of all patients in each group. It is possible that the 

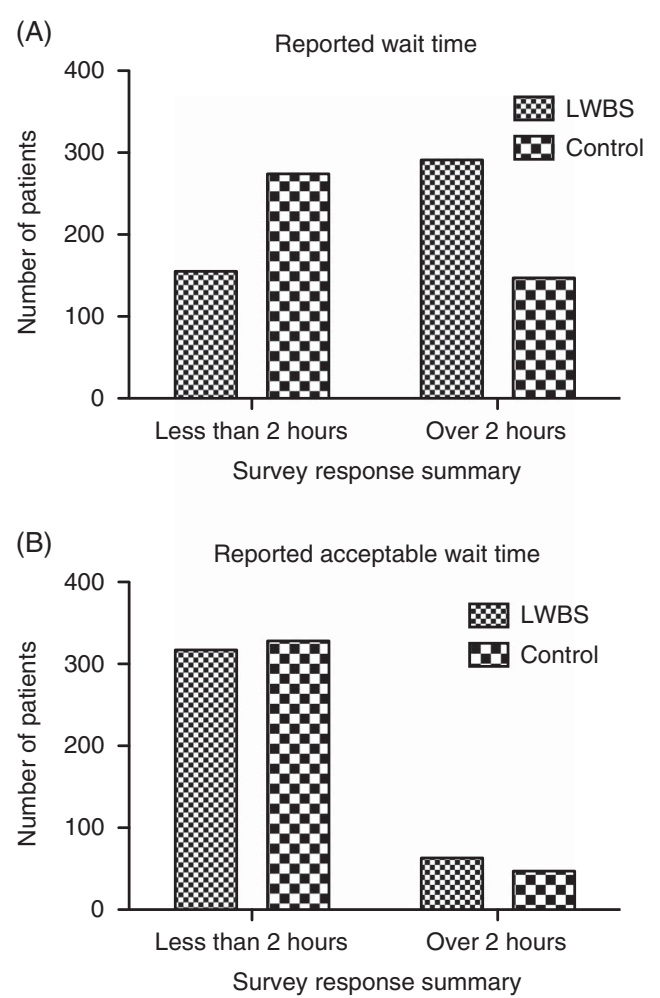

Figure 3, A and B. Comparison responses for $A$ : How long did you wait before being seen (or leaving)? and $B$ : What is the length of time you feel you should have waited with your condition?

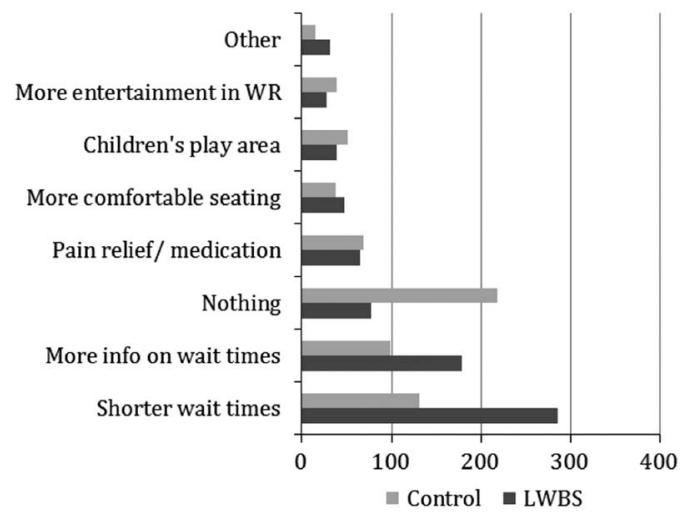

Figure 4. Responses for "What could we have done to make your wait easier and more pleasant?" and "What could we have done to make you wait longer to see a doctor?"

experiences of those who did participate were not representative of the entire study sample; however, each group was satisfactorily matched. Telephone surveys were collected retrospectively, which may have led to recall bias. Estimates of perceived wait times were given in ranges, which may lead to data accuracy problems; however, the use of ranges are pragmatic and easily understood by the participants.

\section{CONCLUSIONS}

ED LWBS patients had similar opinions, experiences, and expectations as controls. Despite otherwise closely matched patients' characteristics, LWBS patients believed that the wait times were longer than expected. Suggested improvements included shorter wait times and provision of more information on wait times. LWBS patients may be more likely to self-triage to alternate care: they do so sooner and in higher proportion but were less likely to be admitted to the hospital for the presenting problem. Both study groups contained patients requiring admission, demonstrating that LWBS patients do carry risk. Further study should explore relationships between LWBS patients, ED boarding rates, and physician initial assessment times.

Author contributions: $\mathrm{PA}$ and J Fraser contributed to project design, ethics application, data acquisition and analysis, and final project composition. AG contributed to project design, ethics application, and data acquisition and analysis. J French, $\mathrm{RM}$, and MH contributed to project design and final project composition.

Acknowledgements: We wish to acknowledge the assistance of Kerry Betts, Debra Pitts, Tammy Lawson, and Kim David, who helped perform the telephone surveys and reviewed the manuscript.

Competing interests: None declared.

\section{REFERENCES}

1. Khangura JK, Flodgren G, Perera R, et al. Primary care professionals providing non-urgent care in hospital emergency departments. Cochrane Database Syst Rev 2012;11:CD002097.

2. Fayyaz J, Khursheed M, Mir MU, et al. Missing the boat: odds for the patients who leave ED without being seen. BMC Emerg Med 2013;13(1):1.

3. Lucas J, Batt RJ, Soremekun OA. Setting wait times to achieve targeted left-without-being-seen rates. Am 7 Emerg Med 2014;32(4):342-5.

4. Ding R, Jung J, Kirsch T, et al. Uncomplicated emergency department care: patients who leave against medical advice. Acad Emerg Med 2007;14(10):870-6.

5. Guttman A, Schul M, Vermeulen M, et al. Association between waiting times and short term mortality and hospital admissions after departure from emergency department: population based cohort study from Ontario, Canada. Br Med 7 2011;342:d2983.

6. Rowe BH, Channan P, Bullard M, et al. Characteristics of patients who leave emergency departments without being seen. Acad Emerg Med 2006;13(8):848-52. 
7. Kennedy M, MacBean CE, Brand C, et al. Review article: leaving the emergency department without being seen. Emerg Med Australas 2008;20(4):306-13.

8. Canadian Institute of Health Information. Understanding emergency department wait times: who is using the emergency department and how long do they wait? Canadian Institute for Health Information, Ottawa; 2005. Available at: https://secure.cihi.ca/free_products/Wait_ times_e.pdf.
9. Innes $\mathrm{K}$, Jackson D, Plummer $\mathrm{V}$, et al. Care of patients in emergency department waiting rooms - an integrative review. 7 Adv Nurs 2015;71(12): 2702-14.

10. Zeithaml VA, Berry LL, Parasuraman A. The nature and determinants of customer expectations of service. 7 Acad Market Sci 1993;21(1):1-12.

11. Blake DF, Dissanayake DB, Hay RM, et al. "Did not waits": a regional Australian emergency department experience. Emerg Med Australas 2014;26(2):145-52. 